\title{
Baitshyness retention in rats with olfactory-bulb ablations
}

\author{
STEPHEN H. HOBBS \\ Augusta College, Augusta, Georgia 30904 \\ and \\ RALPH L. ELKINS \\ VA Hospital, Augusta, Georgia 30904
}

\begin{abstract}
Bilateral lesions of the main and accessory olfactory bulbs were produced to assess the effects of bulbar damage on the retention of preoperatively conditioned flavor aversions. Bulbectomized rats retained the aversion as well as control animals and showed comparable rates of extinction. Additionally and unexpectedly, flavor aversions developed in some surgical control rats which had not been administered the illness-inducing drug.
\end{abstract}

Considerable recent evidence now suggests that the mammallian olfactory system serves as more than just a specific sensory processor. This evidence, reviewed by Cain (1974), rests primarily upon the observation that peripherally induced anosmia frequently does not result in the same behavioral changes as those produced by direct surgical insult to the olfactory bulbs. With respect to the acquisition of aversions to flavors which have been paired with internal malaise (baitshyness), at least partial attenuation results from bilateral olfactory-bulb lesions in both rats and hamsters, even if the posterior bulbar layers are spared (e.g., Dinc \& Smith, 1966; Hankins, Garcia, \& Rusiniak, 1973; Hobbs, Clingerman \& Elkins, 1976; Elkins \& Hobbs, Note 1). Conversely, no disruption of baitshyness occurs if anosmia is produced by intranasal application of zinc sulfate (Dinc \& Smith, 1966; Hankins et al., 1973). Thus, a reduction or loss of odor cues does not account for disrupted baitshyness acquisition following lesions of the olfactory bulbs.

Domjan (1973) reported that peripheral anosmia also has no effect on the continued maintenance of aversions conditioned prior to zinc sulfate treatment. In light of the behavioral differences frequently encountered following peripherally as opposed to bulbectomy-induced anosmia, there is no clear rationale for predicting whether or not lesions of the olfactory bulbs would have similar effects on baitshyness retention. Therefore, the function of the bulbs in baitshyness would be clarified by evaluating their role in the retention, as well as acquisition process. The present study investigated this problem by comparing bulbectomized and control rats on the

This report was funded by VA Project MRIS 2389-01. Address reprint requests to Stephen H. Hobbs, Department of Psychology, Augusta College, Augusta, Georgia 30904. retention of a flavor aversion established prior to surgery.

\section{METHOD}

The subjects were male Sprague-Dawley rats (Flow Laboratories, Dublin, Virginia), approximately 180 days old and weighing $375-495 \mathrm{~g}$ at the beginning of the study. The animals were individually housed under a natural light-dark cycle and controlled temperature. Random procedures were used in assigning rats to experimental groups.

Following $24 \mathrm{~h}$ of water deprivation, all subjects were given access to a novel fluid, a $.05 \%$ solution $(w / v)$ of sodium saccharin in tap water. Saccharin bottles were left on the home cage for a minimum of $10 \mathrm{~min}$, and for at least $5 \mathrm{~min}$ after the onset of drinking. Five minutes after saccharin removal, the rats assigned to baitshyness conditioning received $25 \mathrm{mg} / \mathrm{kg}$ IP injections of cyclophosphamide (Cytoxan ${ }^{\circledR}$, Mead Johnson Laboratories) while saline-control animals received similar injections of isotonic saline. Saccharin was returned to the cage following these injections and remained the sole fluid source until two 24-h preference tests were begun the following day. Two bottles, one containing the saccharin solution and the other tap water, were simultaneously presented on the home cage. Positions were reversed for the second 24-h test. Fluid intake was determined by comparing bottle weights taken before and after each test. Preference scores were computed to reflect the percentage of saccharin solution ingested relative to total fluid intake. Saline-injected rats which rejected the saccharin and drug-injected rats which preferred the saccharin were excluded from further experimentation.

Surgery was performed on the day of the second preference test. Subjects from both the saline- and cyclophosphamide-injected conditions were assigned to unoperated, sham-surgery, or olfactorylesion groups. Surgery was performed under Equithesin anesthesia $(3.75 \mathrm{cc} / \mathrm{kg})$. Animals were placed in a stereotaxic instrument, and the olfactory bulbs were exposed by removal of the overlying skull with a trephine drill. The olfactory bulbs and adjacent connecting tissue were bilaterally aspirated through a glass pipette. Surgery was performed under visual guidance aided by a stereomicroscope. The resulting cavity was lightly packed with Gelfoam and the incision sutured. Procedures for the surgicalcontrol group were identical except that care was taken not to penetrate the dura mater and no tissue was aspirated.

Two-bottle preference tests were again initiated following 2 days of surgical recovery. Positions of the saccharin and water bottles 
were reversed daily for a total of 16 postsurgical, 24-h evaluations. Preference scores were computed as discussed above. At the conclusion of preference testing, animals were administered a lethal anesthetic dose and perfused with saline and Formalin. Brains were removed and stereoscopically examined to determine lesion extent. After excluding one rat which had extensive damage to the frontal poles and another which had only minimal olfactory-bulb damage, final group sizes were: saline, unoperated-6; saline, sham surgery -5 ; saline, bulbectomy -4 ; drug, unoperated-5; drug, sham surgery -5 ; and drug, bulbectomy -5 .

\section{RESULTS}

Retention of the conditioned taste aversion was not impaired by lesions of the olfactory bulbs. These results are presented in Figure 1, together with preoperative preference scores for comparative purposes, and in Table 1. Bulbectomized rats showed excellent retention of the aversion and a rate of extinction comparable with other conditioned animals. Preference scores were subjected to an analysis of variance (weighted-means solution) which revealed no significant effect of the surgical conditions $(F=1.07$, df $=2 / 24, p>.25$ ). As expected, drug effects were statistically significant $(\mathrm{F}=24.34$, $\mathrm{df}=1 / 24$, $p<.01$ ), as were both the effect of repeated measures and the interaction of drug conditions with repeated measures $(F=2.49, \mathrm{df}=7 / 168, \mathrm{p}<.05 ; \mathrm{F}=9.80$, $\mathrm{df}=7 / 168, \mathrm{p}<.01$, respectively). Other interactions were not statistically significant.

It would appear from inspection of Figure 1, that aversions to the saccharin solution gradually developed in the unconditioned, operated-control group. Although this trend was not statistically reliable as indicated by an insignificant three-way interaction, no animals in this group displayed strong saccharin preferences after the second day of testing, and three clearly developed saccharin aversions (see Table 1). Similar saccharin rejection was seen in but one of the other saline-injected rats. In contrast, conditioned groups of animals showed little difference in the overall magnitude of aversion. By the end of testing, no more than two animals in each of the conditioned groups were showing greater saccharin than water intake.

Table 1

Saccharin Preference Scores Across All Postoperative Testing

\begin{tabular}{lcrc}
\hline \multicolumn{1}{c}{ Group } & Mean & Range & Aversions* \\
\hline Saline-injected & & & \\
$\quad$ Normal $(\mathrm{n}=6)$ & 82.4 & $40.4-95.0$ & 1 \\
Operated Control $(\mathrm{n}=5)$ & 46.6 & $19.9-80.5$ & 3 \\
$\quad$ Bulbectomized $(\mathrm{n}=4)$ & 77.4 & $68.4-92.6$ & 0 \\
Drug-injected & & & \\
$\quad$ Normal $(\mathrm{n}=5)$ & 22.5 & $6.0-79.1$ & 5 \\
Operated Control $(\mathrm{n}=5)$ & 29.9 & $10.4-57.4$ & 5 \\
Bulbectomized $(\mathrm{n}=5)$ & 24.8 & $5.5-64.2$ & 5 \\
\hline
\end{tabular}

*Number of animals in each group which had a preference score of less than 50 on any four consecutive postoperative testing days.

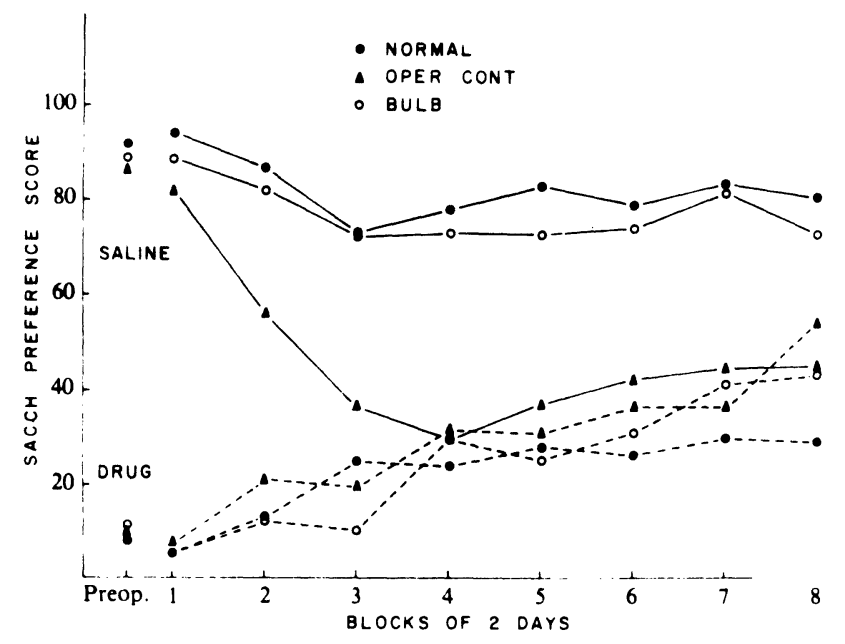

Figure 1. Mean saccharin preference scores from pre- and postoperative testing averaged across 2-day blocks of time.

Bulbectomized rates were found to have most of the main and accessory bulbar tissue removed bilaterally. The lesion typically extended into the peduncular region, occasionally resulting in minor damage to the ventral surface of the frontal cortex. Lesions of the saline- and drug-injected groups were indistinguishable with respect to both size and locus of destruction. Operated-control animals were found to be free of neural destruction.

\section{DISCUSSION}

These results clearly indicate that the olfactory bulbs of rats are not required for the maintenance of taste aversions conditioned prior to bulb removal. This finding can be viewed as consistent with Cain's (1974) hypothesis that the olfactory bulbs may participate in a forebrain arousal circuit. During baitshyness acquisiton, the bulbs may normally facilitate the association of gustatory cues with visceral distress through its arousal function, a function not critical for maintaining already established aversions. Associative enhancement via increased arousal (or some other as yet unspecified facilitatory process) could account for our unpublished observations that the degree to which bulbectomy disrupts baitshyness acquisition is inversely related to the dose level of the conditioning agent. Relatively weak cyclophosphamide doses (e.g., $12.5 \mathrm{mg} / \mathrm{kg}$ ) consistently produced an acquisition deficit in bulbectomized rats, but this deficit was overridden by strong doses (e.g., 75 or $100 \mathrm{mg} / \mathrm{kg}$ ). It is important to emphasize that the specific nature of nonsensory olfactory-bulb contributions to taste aversion conditioning remains to be determined. Cain's (1974) arousal hypothesis is advanced simply to illustrate one of the possibilities that could integrate current acquisition and retention data.

The lesions reported here destroyed both the main 
and accessory bulbar layers, structures clearly dissociable in terms of peripheral input and central connections (Alberts, 1974; Scalia \& Winans, 1975; Winans \& Scalia, 1970). The main olfactory bulb receives primary olfactory fibers through the cribriform plate, while the accessory olfactory bulb receives fibers of the vomeronasal nerve originating in the vomeronasal (Jacobson's) organ. While the functional significance of the vomeronasal system remains unclear, the present study would suggest that it is not critical for the retention of conditioned flavor aversions. However, since total bulbectomies do disrupt baitshyness acquisition, the vomeronasal system may contribute to that process. The main and accessory olfactory bulbs also appear to project to different portions of the corticomedial amygdala. This is of interest since Nachman and Ashe (1974) recently found that lesions centered in the adjacent basolateral amygdala disrupted both the acquisition and retention of conditioned taste aversions. However, examination of their pictorial reconstruction suggests that at least some lesions infringed on the posterolateral cortical amygdaloid nucleus to which the main olfactory bulb projects and on the medial amygdaloid nucleus to which the accessory olfactory bulb projects. Discrete lesions of these and other sites of differential input from the main and accessory olfactory bulbs (cf. Scalia \& Winans, 1975) may further clarify the neuroanatomical substrates of baitshyness phenomena.

Further studies of the amygdala are of additional importance since it is the only structure studied to date which has been implicated in the disruption of both baitshyness acquisition (Elkins, 1970; Kemble \& Nagle, 1973; McGowan, Hankins, \& Garcia, 1972; Nachman \& Ashe, 1974; Rolls \& Rolls, 1973) and retention (Nachman \& Ashe, 1974). Memory of preoperatively conditioned flavor aversions is not attenuated by lesions of area postrema (Branca, Campbell, \& Margules, 1972), the lateral hypothalamus (Schwartz \& Teitelbaum, 1974), or ventromedial hypothalamus (Gold \& Proulx, 1972). These are all areas in which lesions may, under some experimental conditions, disrupt baitshyness acquisition (Berger, Wise, \& Stein, 1973; Gold \& Proulx, 1972; Peters \& Reich, 1973; Roth, Schwartz, \& Teitelbaum, 1973; but see Weisman, Hamilton \& Carlton, 1972).

The development of aversions by some of the unconditioned, operated-control animals suggests that the design of the present study may have permitted the association of the still relatively novel saccharin solution with surgically related internal malaise. If adventitious conditioning was responsible for these animals' saccharin rejection, then bulbectomy, even though it, too, is accompanied by surgical trauma, should attenuate the effect, as demonstrated by previous research cited earlier. Inspection of
Figure $i$ and Table 1 reveals that this is, in fact, what occurred in the present experiment. Other explanations of saccharin rejection by sham-surgical rats are possible and are being explored in additional investigations.

\section{REFERENCE NOTE}

1. Elkins, R. L., \& Hobbs, S. H. Dissociation of shock-motivated compartment avoidance and drug-induced flavor aversions following selective olfactory system lesions. Presented at the Fourth Annual Meeting of Society for Neuroscience, St. Louis, Missouri, 1974.

\section{REFERENCE}

Alberts, J. R. Producing and interpreting experimental olfactory deficits. Physiology and Behavior, 1974, 12, 657-670.

Berger, B. D., Wise, C. D., \& Stein, L. Area postrema damage and bait shyness. Journal of Comparative and Physiological Psychology, 1973, 82, 475-479.

Branca, R. T., Campbell, C. P., \& Margules, D. L. Rats with area postrema lesions show the lateral hypothalamic syndrome and indications of enhanced conditioned taste aversions. Federation Proceedings, 1972, 31, 397. (Abstract)

CaIN, D. F. The role of the olfactory bulb in limbic mechanisms. Psychological Bulletin, 1974, 81, 654-671.

Dinc, H. I., \& Smith, J. C. Role of the olfactory bulbs in the detection of ionizing radiation by the rat. Physiology and Behavior, 1966, 1, 139-144.

Domjan, M. Role of ingestion in odor-toxicosis learning in the rat. Journal of Comparative and Physiological Psychology, 1973, 84, 507-521.

ElkINs, R. L. Effects of limbic lesions on irradiation contingent saccharin preference shifts. Unpublished doctoral dissertation, University of Georgia, 1970.

Gold, R. M.. \& PRouIx, D. M. Bait-shyness acquisition is impaired by VMH lesions that produce obesity. Journal of Comparative and Physiological Psychology, 1972, 79, 201-209.

Hankins, W. G., Garcia, J., \& Rusiniak, K. W. Dissociation of odor and taste in bait shyness. Behavioral Biology, 1973, 8, 1-13.

Hobbs, S. H., Clingerman, H. K., \& Elkins, R. L. Illnessinduced taste aversions in normal and bulbectomized hamsters. Physiology and Behavior, 1976, in press.

Kemble, E. D., \& NAGEl, J. A. Failure to form a learned taste aversion in rats with amygdaloid lesions. Bulletin of the Psychonomic Society. 1973, 2. 155-156.

McGowan, B. K., Hankins, W. G., \& Garcia, J. Limbic lesions and control of the internal and external environment. Behavioral Biology, 1972, 7, 841-852.

NACHMAN, M., \& Ashe, J. H. Effects of basolateral amygdala lesions on neophobia, learned taste aversions, and sodium appetite in rats. Journal of Comparative and Physiological Psychology, 1974, 87, 622-643.

Peters, R. H., \& Reich, M. J. Effects of ventromedial hypothalamic lesions on conditioned sucrose aversions in rats. Journal of Comparative and Physiological Psychology, 1973, 84, 502-506.

Rolls, B. J., \& Rolls, E. T. Effects of lesions in the basolateral amygdala on fluid intake in the rat. Journal of Comparative and Physiological Psychology, 1973, 83, 240-247.

Roth, S. R., Schwartz, M., \& Teitelbaum, P. Failure of recovered lateral hypothalamic rats to learn specific food aversions. Journal of Comparative and Physiological Psychology, 1973, 83, 184-197.

Scalia, F., \& Winans, S. S. The differential projections of the olfactory bulb and accessory olfactory bulb in mannals. Journal of Comparative Neurology, 1975, 161, 31-56. 
Schwartz, M.. \& Teitelbaum. P. Dissociation between learning and remembering in rats with lesions in the lateral hypothalamus. Journal of Comparative and Physiological Psychology, 1974. 87, 384-398.

Weisman. R. N.. Hamilton. L. W.. \& Carlton, P. Increased conditioned gustatory aversion following VMH lesions in rats.
Physiology and Behavior, 1972, 9, 801-804.

Winans, S. S., \& Scalia. F. Amygdaloid nucleus: New afterent input from the vomeronasal organ. Science, 1970, 170, 3.30-3.32.

(Received for publication January 2(! $10^{-7} \mathrm{n}$ : accepted April 19.1976.) 